\title{
Generational differences in psychological ownership
}

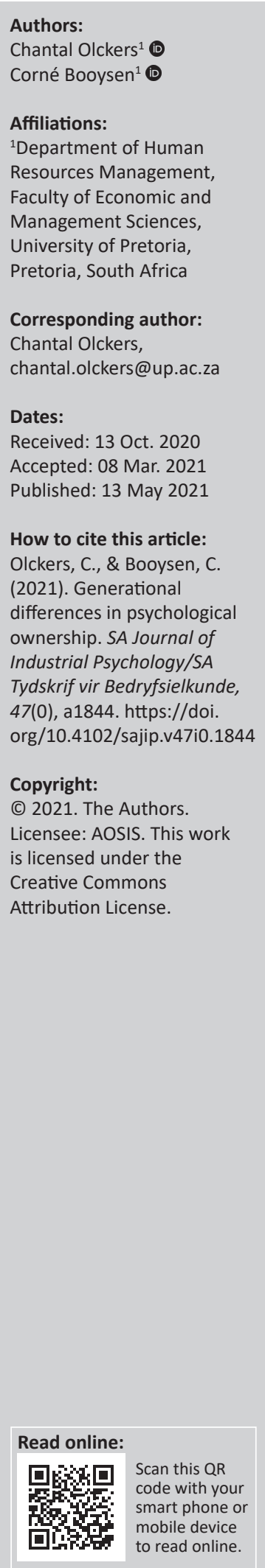

Orientation: Several generational groups are employed in the workplace today, each with distinctly different attitudes, values and work behaviours. Little is known about how generational cohorts differ in terms of psychological ownership.

Research purpose: The purpose of this study was to investigate the measurement equivalence of the South African Psychological Ownership Questionnaire (SAPOS) across three generational cohorts (Baby Boomers, Generation Xers and Generation Yers).

Motivation for the study: Before meaningful inferences and comparisons can be made about psychological ownership across the generational cohorts, it is essential to ensure that the psychological ownership scale measures the same trait across all three generational cohorts.

Research approach/design and method: A cross-sectional study was conducted with a convenience sample of 945 skilled respondents employed in various public and private organisations employing a multigroup confirmatory factorial analytical approach.

Main findings: The tripartite model of the SAPOS, comprising identity, responsibility and autonomy, was confirmed across the three generational cohort. Measurement invariance was established on configural, metric and scalar level across the three generational cohorts.

Practical/managerial implications: The three generational cohorts perceive the items as was measured by the psychological ownership scale in the same way. Meaningful comparisons can thus be made between the groups and organisations can tailor their interventions to enhance the levels of psychological ownership of each of these generational cohorts.

Contribution/value-add: This study is one of the first to provide empirical evidence of generational differences in respect of psychological ownership and to evaluate the measurement equivalence of a psychological ownership inventory across generational cohorts.

Keywords: Baby Boomers; generational cohorts; Generation X; measurement equivalence; millennials.

\section{Introduction}

The working world is more diverse than ever before. Modern organisations showcase diversity in various forms ranging from different cultures, nationalities, genders and ethnicities, through to different capabilities and generations (Massingham \& Chandrakumara, 2019; Rani \& Samuel, 2019; Suomäki, Kianto, \& Vanhala, 2019). Despite the value that a diverse workforce poses, managing it effectively remains challenging in today's work environment. The increasing mix of generations brings more complexity to the workplace because of more pronounced differences between generational cohorts that influence their work-related attitudes, values and behaviour at work (Weeks, Weeks, \& Lomg, 2017). These differences can be observed in experience, education, views of authority, work values, the meaning of work and work-life balance and overall work ethic (Bosco \& Harvey, 2013; Suomäki et al., 2019). Failure to recognise the ideological and perceptual differences between the generational cohorts can lead to negative organisational outcomes such as conflict and misunderstandings in the workplace, poor working relationships and employee well-being, reduced employee productivity, lower innovation and fewer organisational citizenship behaviours (Becton, Walker, \& Jones-Farmer, 2014; Burke, Cooper, \& Antoniou, 2015; Massingham \& Chandrakumara, 2019). All these aspects thus have an impact on the effectiveness of an organisation (Van der Walt, Jonck, \& Sobayeni, 2016). 
Generational cohorts are individuals from the same generation. Each of these generations has been exposed to the same circumstances and environmental events during their adolescence and early adulthood, which have shaped their behaviour patterns and way of thinking (Van der Walt et al., 2016). One should, however, acknowledge individual differences and guard against generalising behaviour. There seem to be various classifications in literature demarcating one generation from another across countries. The following classification proposed by most authors, as was used in this study are Baby Boomers (born between 1946 and 1964), Generation Xers (born between 1965 and 1980), Generation Yers or Millennials (born between 1981 and 1995) and Generation Zers (born between 1997 and 2012) (Becton et al., 2014; Smeak, 2020). A similar classification was used in a South African study conducted by Heyns and Kerr (2018). For the purpose of this study and based on the distribution of the sample, only three cohorts were included in the study, namely the Baby Boomers (called Boomers), Generation $X$ (called Gen X) and Generation Y (called Millennials).

Intergenerational differences influence all aspects of people management, such as recruitment, training and development, career development, job satisfaction and working arrangements. According to Bencsik, Horváth-Csikós and Juhász (2016), managers should practise intergenerational management. For managers to recognise and to handle problems originating from the cooperation of different generations, they have to be aware of and sensitive to individual generational characteristics. Strategies aimed at attracting, engaging and retaining employees of various generational cohorts have become strategically important (Durocher, Bujaki, \& Brouard, 2016; Suomäki et al., 2019). It is essential for employers to employ intervention strategies and to develop techniques that can prevent or manage conflict and reduce the number of misunderstandings so that different generational cohorts can work together successfully to maximise the productivity and profitability of the organisation (Wood, 2019). Managers who, for example, adopt a transformational leadership style that promotes relationships and meets individual needs and who follow a coaching, mentoring and developing approach, might be better equipped to deal with generational differences. Other strategies that organisations could implement are to modify their web communications, to become more paperless and to implement flexible working schedules to adapt to various generations' career expectations (Durocher et al., 2016).

The changes that took place in the workplace have also changed employees perceptions regarding the meaning of work. Reduction in the psychological attachment towards the organisation is an example of such a change. This is especially true for Millennials who tend to be job hoppers and who see "employee "careerism" as a mode to build their careers' (Rani \& Samuel, 2019, p. 259). A construct that has been associated with increasing employees' emotional attachment towards their organisation is psychological ownership. Psychological ownership is defined as a state where an individual feels as though the object of ownership or a piece of that object belongs to them. This definition best describes an individual's feeling of 'this is MINE!' (Pierce, Kostova, \& Dirks, 2001, p. 301), which is a feeling that the individual experiences when he or she feels (or feel to a certain extent) that a target (e.g. an organisation) is theirs. Psychological ownership is a cognitive-affective construct based on individuals' feelings of possessiveness towards and their psychological attachment to objects that are material or immaterial (Pierce et al., 2001). Psychological ownership has been associated with: (1) increased organisational commitment, (2) greater individual accountability, (3) increased extra-role credibility, (4) reduced turnover, (5) increased job satisfaction, (6) improved performance, (7) improved well-being, (8) increased organisational-based self-esteem and more engaged employees (Avey, Avolio, Crossley, \& Luthans, 2009; Chai, Song, \& You, 2020; Chen et al., 2020; Olckers, Du Plessis, \& Casaleggio, 2019).

The literature indicates that generational cohorts diverge in terms of numerous behavioural characteristics and how they attach to work (Bosco \& Harvey, 2013; Durocher et al., 2016; Wood, 2019). For example, it was found that Millenials seem to have a much lower level of commitment towards their organisations and display higher turnover intentions compared with Gen X and the Boomers. They also had the highest number of job changes amongst all generations (Lyons, Schweitzer, \& Ng, 2015; Rani \& Samuel, 2019). All of these generational behavioural characteristics could be influenced by psychological ownership (Pierce et al., 2001). Evidence of the importance of psychological ownership as a predictor of workplace motives, attitudes and behaviours has been provided in a large body of literature over the past decade (e.g. Chai et al., 2020; Chen et al., 2020; Jussila, Tarkiainen, Saestedt, \& Hair, 2015; Olckers et al., 2019).

Based on this discussion, when considering the retention of people in an organisation, it is essential to focus on the psychological attachment factors relating to every generational cohort. Olckers and Du Plessis (2012) suggested that the creation of a sense of ownership amongst employees may potentially increase their intention to remain in the organisation. This was echoed by Jafri (2015), who discovered that ownership could affect employee behaviours, mostly because of its effect on employees' intentions to remain at the organisation. Although several researchers have found differences amongst generations when measuring workrelated attitudes and behaviour (job satisfaction, commitment and intention to quit) (Lyons et al., 2015; Rani \& Samuel, 2019; Twenge, Campbell, Hoffman, \& Lance, 2010), so far the literature has not accounted for how generational cohorts perceive psychological ownership. It is evident from the literature that generation cohorts require different means to activate them at work. Therefore, interventions need to be tailored and strategies need to be implemented to address the cohort's various needs aiming at engaging and retaining them (Sarraf, Abzari, Ali Isfahani, \& Fathi, 2017). Given psychological ownership's positive organisational implications and its positive consequences for talent management (Avey et al., 2009; Olckers \& Du Plessis, 2012), interventions can be 
tailored to enhance psychological ownership across the generation cohorts. These interventions can only be tailored if psychological ownership can be accurately measured across generations. When planning to compare observations across generational cohorts, it is essential to ensure that the scale that is being used is measuring the same trait (psychological ownership) across these cohorts. Measurement invariance should thus be examined. According to Chen (2007), conclusions drawn from a study may be biased or invalid if the measures that researchers rely on do not have the same meanings across different groups.

The literature on psychological ownership and generational cohorts is limited. This study is one of the first to provide empirical evidence of generational differences in respect of psychological ownership. Also, this study is the first to evaluate the measurement equivalence of a psychological ownership inventory across generational cohorts. Van der Walt et al. (2016) emphasised the need to conduct generational cohort studies, especially in developing countries such as South Africa. Generational cohorts in South Africa have experienced, been influenced by and perceived historical events in different ways. The majority of generational research studies have been conducted in developed Western countries, which raises concern regarding the generalisability of their findings to developing countries such as South Africa (Heyns \& Kerr, 2018).

Therefore, the purpose of this study was to examine the measurement equivalence of a psychological ownership inventory across three generations to determine whether these generations responded to the content of relevant items in a similar manner.

\section{Literature review \\ Psychological ownership}

Van Dyne and Pierce (2004) observed that psychological ownership is a person's possessive feeling towards an organisation that affects that organisational member's attitude and behaviour. As mentioned earlier, psychological ownership refers to the feeling an individual experiences that a target, or a piece of that target, is theirs (i.e. 'this is MINE') (Pierce et al., 2001, p. 299). The basis of psychological ownership is the individual's sense of possession of an object (Jussila et al., 2015). Psychological ownership is cognitive and affective, because it indicates an individual's awareness, thoughts and beliefs concerning the possessed target and the personal meaning and emotion attached to it (Pierce et al., 2001). Psychological ownership can be directed to numerous objects (or targets) such as an organisation, a job or a work project, causing the target(s) to turn into an extension of the self and become closely associated with the individual's identity (Pierce, Kostova, \& Dirks, 2003).

The literature on psychological ownership identifies the sense of individual possession as rooted in three human needs: (1) efficacy and effectance - the individual feels efficacious and in control of the target or object,
(2) self-identity - the target becomes part of the individual's self-identity when they establish perceived ownership, (3) belongingness (having a place to 'dwell') - attachment to a target makes an individual feel 'at home' (Pierce et al., 2001, 2003). These needs can be seen as the motivational factors that serve to set individuals on their path towards psychological ownership (Jussila et al., 2015).

\section{Generations and psychological ownership}

Individuals require psychological ownership resulting from innate motives relating to efficacy and effectance, selfidentity and belongingness (having a place to dwell). Several factors influencing psychological ownership include the strength of the motives, personality, a strong sense of self and personal values (Pierce et al., 2003). The strength of motives is an indication of the likelihood that a feeling of psychological ownership will develop. Scholars have suggested that Boomers, Gen X and Millennials all have strong motives relating to their organisations because they have certain expectations about the development of their careers (Srinivasan, 2012).

Personality is another factor that can influence the development of psychological ownership. Personality traits determine the way individuals pursue an ownership relationship with objects. Boomers, for example, will develop a feeling of psychological ownership when they are personally involved in their organisation and when they learn new skills in a creative way (Gursoy, Chi, \& Karadag, 2013). Gen X prefers to have control and power over an object rather than a close relationship with it because they are more committed to their careers than to their organisation. Millennials regard technological factors and a wellestablished lifestyle as important (Durocher et al., 2016). It can thus be assumed that Millennials will develop a sense of psychological ownership if the organisation can satisfy their technological and lifestyle requirements.

The third factor influencing psychological ownership is a strong sense of self (i.e. high self-esteem). Pierce et al. (2003) suggested that individuals with a strong need to achieve selfactualisation may pursue intrinsic targets. In contrast, individuals with a weaker self-concept are more prone to pursue materialistic targets. Boomers and Millennials value status and they desire extrinsic rewards for their loyalty and commitment towards their organisation, whereas Gen X enjoy intrinsic rewards that are less tangible (Cogin, 2012). Therefore, Gen X can be described as a group of individuals with a high self-concept, resulting in a higher tendency to develop a sense of psychological ownership.

The influence of the last factor, which is personal values, varies depending on the cohort involved. Boomers' personal values are of immense importance to them because they believe that their values form part of their core identity and that personal values and work ethics must be aligned (Wong, Gardiner, Lang, \& Coulon, 2008). Millennials were born at a time when deviation was allowed in personal values, 
resulting in a perception that personal values do not have to match work ethics or affect the route to success (Van der Walt et al., 2016). Lu and Gursoy (2016) observed that Gen X tend to leave the organisation when they are not satisfied. Similarly, Millennials tend to leave organisations to find a fun environment with various personal growth opportunities (Calk \& Patrick, 2017). However, Boomers tend to remain at one organisation as they value loyalty towards the organisation (Cogin, 2012; Rani \& Samuel, 2019). Personal values make particular objects more-or-less esteemed. From a self-concept perspective, individuals may strive to increase their feelings of self-worth by psychologically possessing items that are the most significant to them. Individuals are likely to feel ownership over those objects (such as their organisation in the case of Boomers) that are considered to be the most important according to their values (Pierce et al., 2003).

Psychological ownership is also influenced by the idea of the 'place for psychological ownership' (Jussila et al., 2015). This entails that some individuals might experience objects more closely than others, especially if these objects have more emotional value for these individuals. Thus, targets to which individuals, in general, attach more meaning are more likely to become targets of psychological ownership. Research conducted by Calk and Patrick (2017) is of relevance here. They established that Millennials need to see the meaning and added value of their contributions to the work before they take on full responsibility. Thus, when Millennials identify meaning in their work, the piece of work is likely to become a target of ownership.

Although personal characteristics could have an influence on the development of psychological ownership, psychological ownership per se has an influence on personal attitudes and behaviours (Pierce \& Jussila, 2010). For example, if an employee perceives that a change concerning a target (for which the employee feels ownership) is self-initiated, evolutionary and additive, the employee .will be positively oriented towards that change. The converse is also noticeable: employees will have a negative orientation towards change when they perceive it as imposed upon them or threatening, revolutionary and subtractive (Jussila et al., 2015). In a study conducted by Gursoy, Maier and Chi (2008), it was identified that Boomers tend to resist change and react negatively towards imposed change. Durocher et al. (2016) noticed that Gen X and Millennials, on the other hand, expect and demand change within their organisation. Management and change specialists need to take this generational difference into account when they consider changes in an organisation. As Boomers might experience changes negatively, it will result in a loss of psychological ownership and work-related outcomes being negatively affected.

As explained earlier, psychological ownership is a cognitive phenomenon reflecting an individual's beliefs about what is 'mine'. Nonetheless, Pierce and Jussila (2010) observed that 'mine' could also be 'ours'. Millennials tend to be team- oriented and focused on 'collective action' (Calk \& Patrick, 2017; Weeks et al., 2019). Thus, one can conclude that increasing Millennials' teamwork can increase the psychological ownership not only of an individual but also of the individuals within a group, and this increase can simultaneously extend to include other individuals or groups (Weeks et al., 2019; Wong et al., 2008).

Organisations can thus benefit from managing psychological ownership because the possession of psychological ownership can motivate employees to perform at high levels and even inspire them to engage in extra-role behaviours and also organisational citizenship behaviours (Man \& Farquharson, 2015; Olckers \& Du Plessis, 2012). Knowing how generational cohorts differ in their work values and being able to identify how psychological ownership can improve these values might result in better work-related outcomes such as commitment, job satisfaction and the intention to stay with the organisation. As observed by Olckers and Du Plessis (2012), the intangible psychological phenomenon is vital and frequently ignored by human resource practitioners and managers who generally retain talent by employing tangible means.

To make meaningful inferences and comparisons about psychological ownership across the generational cohorts, it is essential to make sure that the psychological ownership scale measures the same trait across all three generational cohorts. Through the use of measurement equivalence, valid and meaningful comparisons can be made between generational cohorts' psychological ownership. Moreover, valid and meaningful interpretations and analyses of these differences will be possible.

\section{Measurement equivalence}

Measurement equivalence, which indicates that the same construct is measured, is important when studying differences or changes amongst groups (Yuan \& Chan, 2016). Measurement equivalence entails that the measurements in different groups are comparable and have the same meanings across different groups (Chen, Sousa, \& West, 2005). Multigroup confirmatory factor analysis (MGCFA) is one of the statistical techniques that could be used for establishing measurement equivalence and involves a sequence of progressively stricter statistical tests that build on each other. 'Only when one form of equivalence has been satisfied can the subsequent test be performed' (Budruk, 2010, p. 29). Firstly, configural invariance should be established. Configural invariance is supported if the data across the different generation cohorts fits a specified model (Yuan \& Chan, 2016). Once configural invariance is established, metric invariance can be tested. Metric invariance testing examines whether factor loadings across groups are equal. If metric invariance is established, it will mean that the different generational cohorts respond to the scale items in the same way. Finally, if metric invariance is satisfied, scalar invariance could be tested. Scalar invariance implies that scores from the different groups have the same factor loading and origin 
(intercept) (Chen et al., 2005). Only after configural, metric and scalar invariance is established can one directly evaluate generational differences concerning psychological ownership.

In this study, structural equation modelling (SEM) was used for employing a MGCFA approach, to determine how psychological ownership was measured within the sample. Secondly, measurement invariance was employed to assess whether psychological ownership was measured or experienced similarly or differently across the three generational cohorts. The study tested for the three levels of measurement invariance, namely configural invariance (similar factor structures), metric invariance (similar factor loadings) and scalar invariance (similar intercepts).

\section{Research methodology Research approach}

The study adopted a quantitative approach with a crosssectional design. According to Spector (2019), there is a renewed interest in cross-sectional studies because they provide insightful information at a single point in time.

\section{Research participants}

The non-probability, purposive convenience sample comprised 945 skilled individuals employed in various public and private organisations in Gauteng, South Africa. The reason for choosing employed individuals was that psychological ownership towards an organisation can only develop in individuals who are employed (Pierce et al., 2001, 2003; Van Dyne \& Pierce, 2004). The participants were grouped into one of the three-generational cohorts based on their year of birth: Boomers $(n=282)$, Gen X $(n=486)$ and Millennials ( $n=177)$ (Becton et al., 2014; Smeak, 2020). The representation of numbers in this study was as expected because Millennials were starting to enter the workforce. In contrast, Boomers were retiring, leaving Gen $\mathrm{X}$ as the dominant generational cohort in current workforce demographics.

Table 1 presents the demographic profile for the sample across the three generational cohorts.

As indicated in Table 1, the black ethnic group was the dominant group in all the generations. Females tended to be the dominant gender in both the Gen $X$ and Millennial groups. Most of the respondents in the sample had postgraduate degrees and occupied positions at different operational levels in various industries in South Africa. Boomers made up the dominant group at senior management level (53.84\%) whereas Gen $X$ made up the dominant group at middle management level (84\%). This was expected as these generational cohorts had been part of the workforce for longer than the Millennials, they tended to have more experience and occupied senior positions in organisations.
TABLE 1: Demographic profile of the sample.

\begin{tabular}{llcccc}
\hline Variable & Grouping & $\begin{array}{c}\text { Boomers } \\
(\boldsymbol{n}=\mathbf{2 8 2})\end{array}$ & $\begin{array}{c}\text { Gen X } \\
(\boldsymbol{n}=\mathbf{4 8 6})\end{array}$ & $\begin{array}{c}\text { Millennials } \\
(\boldsymbol{n}=\mathbf{1 7 7})\end{array}$ & $\begin{array}{c}\text { Total } \\
(\boldsymbol{N}=\mathbf{9 4 5})\end{array}$ \\
\hline Ethnic group & Black people & 154 & 251 & 97 & 502 \\
& Mixed race & 72 & 180 & 45 & 297 \\
& Indian people & 2 & 1 & 1 & 4 \\
& White people & 5 & 46 & 34 & 130 \\
Gender & Male & 143 & 224 & 78 & 445 \\
& Female & 139 & 262 & 99 & 500 \\
Highest & Grade 12 & 39 & 105 & 32 & 176 \\
qualification & Diploma & 102 & 150 & 31 & 283 \\
& Bachelor's degree & 43 & 76 & 47 & 166 \\
& Post-graduate degree & 91 & 148 & 66 & 305 \\
\multirow{2}{*}{ Operational } & Operational level & 53 & 104 & 59 & 216 \\
level & Junior management level & 28 & 75 & 44 & 147 \\
& Middle management level & 66 & 116 & 18 & 200 \\
& Senior management level & 63 & 52 & 2 & 117 \\
\hline
\end{tabular}

Note: Missing values within the demographics have been accounted for.

\section{Research procedure}

The data collection process consisted of two methods for distribution purposes. The questionnaire was electronically distributed to participants via email using a Qualtrics platform, and a hard copy of the questionnaire was made available to participants who were not able to complete the questionnaire electronically. Each anonymous questionnaire included a cover letter inviting the participants to participate voluntarily in the study and highlighting their rights and responsibilities. Participants were assured that their responses would remain confidential and would be used for research purposes only. Permission to conduct the research was obtained from the research institution's research ethics committee.

\section{Measurement instruments}

Olckers (2013) developed the South African Psychological Ownership Questionnaire (SAPOS) for use by South African organisations to measure employees' psychological ownership. Olckers (2013) confirmed the validity of a 35-item four-factor model of the SAPOS comprising the following four dimensions, namely identity, responsibility, autonomy and territoriality. Identity refers to the personal cognitive connection between an individual and a target and reflects the individual's perception of oneness with the target. Responsibility refers to the investment of time, effort and care on the target of ownership in order to maintain, enhance and protect the target. Autonomy refers to the extent to which employees could exercise control over their day-to-day activities, other employees and their personal space. Territoriality refers to a negative behavioural expression of an individual's feelings of ownership towards physical or social objects. Although the SAPOS originally included territoriality as a prevention-oriented dimension, it was excluded in several other studies. The reason for this being the suggestion of several researchers that territoriality should be positioned as a behavioural outcome of psychological ownership rather than as a dimension of psychological ownership (Brown, Crossley, \& Robinson, 2014; Brown, Lawrence, \& Robinson, 2005; Pierce \& Jussila, 2010). Several studies (Aggenbag, 
2015; Brits, 2016) have, however, confirmed a three-factor structure of the SAPOS comprising identity, autonomy and responsibility (Olckers \& Van Zyl, 2017). Brits (2016) refined the SAPOS and confirmed a shortened SAPOS scale with internal reliability of 0.79 for the overall scale. This shortened version of the SAPOS was used in this study. Each item in the SAPOS was measured by using a six-point rating scale ranging from $1=$ strongly disagree to $6=$ strongly agree. An example item of each of the dimensions is as follows: I have considerable opportunity for independence and freedom in how I do my work (Autonomy); I feel a strong linkage between my organisation and me (Identity) and I accept ownership for the results of my decisions and actions (Responsibility). A biographical instrument was also administrated determining the age, sex, qualification and operational level of the employees in their organisation.

\section{Data analyses}

Model fit was determined by using SEM, employing an MGCFA approach. MPlus version 8.2 (Muthén \& Muthén, 2019) was used to process the data. Firstly, descriptive statistics (means, standard deviations, skewness and kurtosis) were employed to determine the distribution of the data and consistency in measurement. The internal consistency of the measuring instrument at both the lower (Cronbach's alpha) and upper (composite reliability) level limits were reported. Composite reliability coefficients $(\rho>0.80)$ were calculated as it is deemed more appropriate for latent variables (Raykov, 2009). The minimum acceptable criterion for Cronbach's alpha was set at $\alpha=0.70$, although values of $\alpha>0.80$ are preferable (Pallant, 2007). The guidelines suggested by Hair, Black, Babin and Andersen (2014) was followed to test for convergent and discriminant validity. Convergent validity is present when (1) the standardised factor loadings of the items is $\geq 0.50$, preferably $\geq 0.70$, (2) the average variance extracted (AVE) is $\geq 0.50$ and (3) construct validity (CR) is $\geq 0.70$. Discriminant validity was determined by the heterotrait monotrait (HTMT) ratio of correlation as was suggested by Henseler, Ringle and Sarstedt (2015). Values close to 1.00 indicate a lack of discriminant validity. The HTMT criterion should be compared with a predefined threshold. There is a lack of discriminant validity if the value of the HTMT criterion is higher that the suggested threshold of 0.85 or 0.90 (Henseler et al., 2015).

Secondly, an MGCFA approach with a comparative fit modelling strategy was employed. The maximal likelihood (ML) estimation method was used to estimate fit for all the models. Maximal likelihood was used because the outcome measures were continuous and the data were normally distributed (skewness $<2$ and kurtosis $<7$; Ryu, 2011). The first phase of the analyses aimed to establish a baseline model for the entire sample by employing a traditional confirmatory factor analysis (CFA) approach. Given the shared variance reported in previous studies, an oblique rotation was employed (Browne, 2001). The second phase of the analyses aimed to systematically compare the model fit for each generational cohort against the baseline model. The following cut-off criteria as suggested by Kline (2016) were employed to assess model fit: the root mean square error of approximation (RMSEA) $\leq 0.08$, standardised root means square residual (SRMR) $\leq$ 0.10 , Tucker-Lewis index (TLI) and the comparative fit index $(\mathrm{CFI}) \geq 0.90$ for good fit.

Finally, we used measurement invariance to assess whether psychological ownership was measured or experienced similarly or differently across three generations (Boomers, Gen X and Millennials). Measurement invariance was assessed by applying increasingly restrictive equality constraints on the three groups through: (1) configural invariance (similar factor structures), (2) metric invariance (similar factor loadings) and (3) scalar invariance (similar intercepts). Metric and scalar invariance are established when the change in model fit between the configural and the metric invariance models and metric and scalar invariance models are equal or smaller than the following tolerable changes if the sample is greater than $300(\mathrm{~N}>300)$ : CFI $(\Delta<0.01)$, RMSEA $(\Delta<0.015)$ SRMR $(\Delta<0.03)$ for configural versus metric and SRMR $(\Delta<0.01)$ for metric versus scalar (Cieciuch \& Davidov, 2015). The least restrictive configural model was used as the baseline model for comparing the increasingly constrained metric and scalar models.

\section{Ethical considerations}

Secondary data were used in this study. Data were collected by Olckers as part of her PhD studies. Ethical approval was granted by the University of Pretoria to collect data. Ethical approval was granted to Booysen to use the data as secondary data in her Master's studies.

\section{Results}

The results of the descriptive statistics, measurement model, factor intercorrelations and measurement invariance across the generation cohorts are reported separately. The results are presented in tables, followed by a brief interpretation of each.

\section{Descriptive statistics}

Table 2 provides an overview of the descriptive statistics (means, standard deviations, skewness and kurtosis) and Cronbach's alpha and composite reliability levels amongst the latent variables across the three different generational cohorts. The results indicated that the data for the constructs were normally distributed (skewness $<2$ and kurtosis $<7$ [Ryu, 2011]). Furthermore, all constructs across all three generational cohorts were measured as reliable and both Cronbach's alpha $(\alpha \geq 0.70)$ and composite reliability $(\rho>0.80)$ scores were found to be higher than the suggested cut-offs. The SAPOS displayed convergent validity because all factor loadings across the generations were significant and above 0.50 (see Table 4), the AVE values of each construct 
was above 0.50 and all CR values where $>0.80$ (see Table 2). Although the AVE values of responsibility for the Gen $X$ group $(\mathrm{AVE}=0.47$ ) and autonomy for the Millennial group $(\mathrm{AVE}=0.49)$ were slightly lower than the suggested cut-off $(A V E \geq 0.05)$, the composite reliabilities were higher than 0.80 and therefore, according to Fornell and Larcker (1981) the convergent validity of the construct is still adequate. Discriminant validity was supported because results of the HTMT showed values below the suggested thresholds of 0.85 and 0.90 . The HTMT results ranged from 0.16 to 0.69 across the generations.

\section{Measurement model}

An MGCFA approach was employed to establish factorial validity across the three generational cohorts. A secondorder three-factor model (with psychological ownership as second-order factor and responsibility, autonomy and identity as first-order factors) SAPOS model was assessed within the overall data set for each individual generational cohort (Boomers, Gen X and Millennials). No items were omitted from the analysis across groups, and the observations (measured items) were treated as indicators for the different latent variables within each measurement model. In order to ensure parsimony and model identification, as well as to enhance model fit, error terms on items 1 and 6 (identity) were allowed to correlate because they were very similar in wording (Wang \& Wang, 2012). Table 3 indicates that this originally hypothesised second-order three-factor CFA model for promotive psychological ownership met the criteria for acceptable model fit suggested by Kline (2016) across the baseline (parent) model $\left(\chi^{2}=485.73 ; d f=115\right.$;
$\mathrm{CFI}=0.95 ; \mathrm{TLI}=0.94 ; \mathrm{RMSEA}=0.05 ; \mathrm{SRMR}=0.03)$, the Boomers model $\left(\chi^{2}=266.9 ; d f=115 ; \mathrm{TLI}=0.94 ; \mathrm{CFI}=0.93\right.$; RMSEA $=0.07$; SRMR $=0.05)$, the Gen $X$ model $\left(\chi^{2}=336.92\right.$; $d f=115 ; \mathrm{TLI}=0.94 ; \mathrm{CFI}=0.93 ; \mathrm{RMSEA}=0.06 ; \mathrm{SRMR}=0.04)$ and the Millennials model $\left(\chi^{2}=211.31 ; d f=115\right.$; TLI = 0.93; $\mathrm{CFI}=0.93$; $\mathrm{RMSEA}=0.07$; $\mathrm{SRMR}=0.06$ ).

Table 4 shows the results for the standardised factor loadings, the associative standard error and the item uniqueness of this CFA model. All items loaded statistically significantly $(p<0.01)$ and sufficiently on the respective latent factors (> 0.50; Wang \& Wang, 2012) across the baseline model and the three generational cohorts' models (ranging from $\lambda=0.58$ to 0.86 ).

Table 5 provides an overview of the standardised latent variable path coefficients for the CFA model and of the explained variance in respect of each generational cohort. The results showed that identity, responsibility and autonomy significantly contributed to psychological ownership across all generational cohorts. The standardised beta coefficients ranged from 0.45 to 0.93 . The variance declared by identity in respect of the baseline model was $79 \%$ $(p<0.01)$, whereas it ranged from $58 \%$ to $86 \%(p<0.01)$ between the three generational cohorts. Similarly, the variance declared by responsibility in respect of the baseline model was $31 \%(p<0.01)$ but ranged from $20 \%$ to $31 \%(p<$ 0.01 ) in respect of the three different generational cohorts. Furthermore, autonomy declared $63 \%(p<0.01)$ of the total variance in psychological ownership, but it ranged from $61 \%$ to $70 \%(p<0.01)$ across the groups.

TABLE 2: Descriptive statistics, reliabilities, average variance extracted values across generations.

\begin{tabular}{|c|c|c|c|c|c|c|c|c|}
\hline Variable & $\overline{\bar{x}}$ & $\sigma$ & Skewness & Kurtosis & $\alpha$ & $\rho$ & AVE & CR \\
\hline \multicolumn{9}{|c|}{ Overall psychological ownership ( $n=947)$} \\
\hline Identity & 4.61 & 0.92 & -1.11 & 1.48 & 0.84 & 0.89 & 0.54 & 0.89 \\
\hline Responsibility & 5.24 & 0.57 & -1.03 & 3.38 & 0.83 & 0.83 & 0.50 & 0.83 \\
\hline Autonomy & 4.63 & 0.92 & -1.13 & 1.80 & 0.87 & 0.87 & 0.54 & 0.87 \\
\hline \multicolumn{9}{|c|}{ Boomers $(n=282)$} \\
\hline Identity & 4.78 & 0.84 & -1.09 & 1.34 & 0.85 & 0.87 & 0.54 & 0.87 \\
\hline Responsibility & 5.30 & 0.55 & -1.08 & 5.11 & 0.87 & 0.87 & 0.57 & 0.87 \\
\hline Autonomy & 4.76 & 0.82 & -1.02 & 1.39 & 0.86 & 0.87 & 0.53 & 0.87 \\
\hline \multicolumn{9}{|l|}{ Gen $X(n=486)$} \\
\hline Identity & 4.51 & 0.96 & -1.02 & 1.14 & 0.83 & 0.87 & 0.53 & 0.87 \\
\hline Responsibility & 5.21 & 0.60 & -1.10 & 2.88 & 0.81 & 0.82 & 0.47 & 0.82 \\
\hline Autonomy & 4.55 & 0.99 & -1.21 & 1.93 & 0.88 & 0.88 & 0.56 & 0.88 \\
\hline \multicolumn{9}{|c|}{ Millennials $(n=177)$} \\
\hline Identity & 4.62 & 0.92 & -1.36 & 2.55 & 0.87 & 0.91 & 0.61 & 0.90 \\
\hline Autonomy & 4.59 & 0.87 & -1.20 & 1.48 & 0.85 & 0.85 & 0.49 & 0.85 \\
\hline
\end{tabular}

$\overline{\mathrm{x}}$, mean; $\sigma$, standard deviation; $\alpha$, Cronbach's alpha; r, composite reliability; AVE, average variance extracted; CR, construct reliability.

TABLE 3: Measurement model fit statistics.

\begin{tabular}{|c|c|c|c|c|c|c|c|c|}
\hline Fit statistic & $\chi^{2}$ & $d f$ & $\mathrm{CFI}$ & TLI & RMSEA & SRMR & AIC & BIC \\
\hline Baseline models & 485.73 & 115 & 0.95 & 0.94 & 0.05 & 0.03 & 39138.80 & 39405.91 \\
\hline Boomers & 266.9 & 115 & 0.94 & 0.93 & 0.07 & 0.05 & 10569.85 & 10769.56 \\
\hline Gen X & 336.92 & 115 & 0.94 & 0.93 & 0.06 & 0.04 & 20640.64 & 20869.62 \\
\hline Millennials & 211.31 & 115 & 0.93 & 0.93 & 0.07 & 0.06 & 6801.04 & 6975.11 \\
\hline
\end{tabular}

$\chi^{2}$, chi-square statistic; $d f$, degrees of freedom; TLI, Tucker-Lewis index; CFI, comparative fit index; RMSEA, root mean square error of approximation; SRMR, standardised root mean square residual; AIC, Akaike information criterion; BIC, Bayes information criterion. 
TABLE 4: Standardised factor loadings $(\lambda)$ and uniqueness $(\delta)$ for the multigroup confirmatory factor analysis across all generational cohorts

\begin{tabular}{|c|c|c|c|c|c|c|c|c|c|c|c|c|c|}
\hline \multirow[t]{2}{*}{ Factor } & \multirow[t]{2}{*}{ Item } & \multicolumn{3}{|c|}{ Baseline model } & \multicolumn{3}{|c|}{ Boomers } & \multicolumn{3}{|c|}{ Gen $X$} & \multicolumn{3}{|c|}{ Millennials } \\
\hline & & $\lambda$ & SE & $\delta$ & $\lambda$ & SE & $\delta$ & $\lambda$ & SE & $\delta$ & $\lambda$ & SE & $\delta$ \\
\hline \multirow[t]{6}{*}{ Identity } & Item 1 & 0.74 & 0.02 & 0.45 & 0.68 & 0.04 & 0.46 & 0.74 & 0.03 & 0.454 & 0.81 & 0.03 & 0.35 \\
\hline & Item 2 & 0.73 & 0.02 & 0.51 & 0.71 & 0.03 & 0.58 & 0.70 & 0.03 & 0.509 & 0.82 & 0.03 & 0.32 \\
\hline & Item 3 & 0.73 & 0.02 & 0.55 & 0.66 & 0.04 & 0.72 & 0.74 & 0.03 & 0.454 & 0.78 & 0.03 & 0.39 \\
\hline & Item 4 & 0.67 & 0.02 & 0.58 & 0.76 & 0.03 & 0.40 & 0.63 & 0.03 & 0.604 & 0.71 & 0.04 & 0.49 \\
\hline & Item 5 & 0.81 & 0.01 & 0.46 & 0.81 & 0.03 & 0.39 & 0.81 & 0.02 & 0.341 & 0.86 & 0.03 & 0.26 \\
\hline & Item 6 & 0.74 & 0.02 & 0.43 & 0.76 & 0.03 & 0.62 & 0.74 & 0.03 & 0.457 & 0.71 & 0.04 & 0.51 \\
\hline \multirow[t]{5}{*}{ Responsibility } & Item 7 & 0.78 & 0.02 & 0.34 & 0.84 & 0.02 & 0.14 & 0.77 & 0.03 & 0.405 & 0.69 & 0.05 & 0.53 \\
\hline & Item 8 & 0.76 & 0.02 & 0.40 & 0.79 & 0.03 & 0.18 & 0.70 & 0.03 & 0.514 & 0.87 & 0.03 & 0.24 \\
\hline & Item 9 & 0.58 & 0.02 & 0.45 & 0.71 & 0.04 & 0.19 & 0.70 & 0.03 & 0.516 & 0.56 & 0.06 & 0.68 \\
\hline & Item 10 & 0.71 & 0.02 & 0.55 & 0.72 & 0.03 & 0.23 & 0.66 & 0.03 & 0.566 & 0.84 & 0.03 & 0.30 \\
\hline & Item 11 & 0.65 & 0.02 & 0.47 & 0.69 & 0.04 & 0.26 & 0.60 & 0.04 & 0.637 & 0.72 & 0.04 & 0.48 \\
\hline \multirow[t]{5}{*}{ Autonomy } & Item 12 & 0.71 & 0.02 & 0.52 & 0.64 & 0.04 & 0.51 & 0.74 & 0.02 & 0.455 & 0.67 & 0.05 & 0.55 \\
\hline & Item 13 & 0.81 & 0.01 & 0.35 & 0.83 & 0.02 & 0.34 & 0.81 & 0.02 & 0.347 & 0.80 & 0.04 & 0.36 \\
\hline & Item 15 & 0.69 & 0.02 & 0.51 & 0.67 & 0.04 & 0.56 & 0.75 & 0.02 & 0.442 & 0.58 & 0.06 & 0.66 \\
\hline & Item 16 & 0.74 & 0.02 & 0.40 & 0.76 & 0.03 & 0.69 & 0.71 & 0.03 & 0.495 & 0.78 & 0.04 & 0.40 \\
\hline & Item 17 & 0.65 & 0.02 & 0.58 & 0.62 & 0.04 & 0.81 & 0.68 & 0.03 & 0.544 & 0.63 & 0.05 & 0.60 \\
\hline
\end{tabular}

Note: All items loaded significantly $(p<0.001)$; No cross-loading items.

$\mathrm{SE}$, standard error for standardised factor loadings.

TABLE 5: Psychological ownership's latent variable path coefficients and variance explained $\left(R^{2}\right)$ for the confirmatory factor analysis model across generations.

\begin{tabular}{llccc}
\hline Path & Variable & Identity & Responsibility & Autonomy \\
\hline Baseline & Loading & 0.89 & 0.55 & 0.79 \\
& SE & 0.03 & 0.03 & 0.03 \\
Boomers & $R^{2}$ & 0.79 & 0.31 & 0.63 \\
& Loading & 0.93 & 0.55 & 0.78 \\
& SE & 0.05 & 0.06 & 0.05 \\
Gen X & $R^{2}$ & 0.86 & 0.31 & 0.62 \\
& Loading & 0.91 & 0.56 & 0.78 \\
& SE & 0.04 & 0.04 & 0.04 \\
Millennials & $R^{2}$ & 0.83 & 0.31 & 0.61 \\
& Loading & 0.76 & 0.45 & 0.84 \\
& SE & 0.09 & 0.08 & 0.09 \\
\hline
\end{tabular}

$\mathrm{SE}$, standard error for standardised factor loadings; $R^{2}$, variance explained.

\section{Factor intercorrelations}

The CFA model produced statistically significant factor intercorrelations across all generational cohorts (baseline: $\mathrm{M}_{\mathrm{r}}=0.55$; Boomers: $\mathrm{M}_{\mathrm{r}}=0.55$; Gen X: $\mathrm{M}_{\mathrm{r}}=0.55$; Millennials: $\left.M_{r}=0.45\right)$. These results are displayed in Table 6 .

\section{Measurement invariance across generational cohorts}

Measurement invariance was assessed across the three generational cohorts, namely between the Boomers $(n=282)$, Gen $X(n=486)$ and Millennials $(n=177)$ models. The first model to be tested was the configural model (M1). Goodness-of-fit results indicated in Table 7 showed adequate fit of the model $\left(\chi^{2}=864.36, d f=348, \mathrm{CFI}=0.93\right.$, $\mathrm{TLI}=0.92, \mathrm{RMSEA}=0.07, \mathrm{SRMR}=0.05)$ to the data, and thus the presence of configural invariance. This means that the same number of factors (identity, responsibility and autonomy) and factor loading pattern is the same across the three generational cohorts. The factor structure across the generational groups is similar, although not identical.
TABLE 6: Factorial intercorrelations.

\begin{tabular}{llccc}
\hline Path & Variable & Identity & Responsibility & Autonomy \\
\hline Baseline & Identity & 1 & - & - \\
& Responsibility & $0.49^{*}$ & 1 & - \\
& Autonomy & $0.71^{*}$ & $0.44^{*}$ & 1 \\
Boomers & Identity & 1 & - & - \\
& Responsibility & $0.51^{*}$ & 1 & - \\
& Autonomy & $0.72^{*}$ & $0.43^{*}$ & 1 \\
Gen X & Identity & 1 & - & - \\
& Responsibility & $0.51^{*}$ & 1 & - \\
& Autonomy & $0.71^{*}$ & $0.42^{*}$ & 1 \\
Millennials & Identity & 1 & - & - \\
& Responsibility & $0.34^{*}$ & 1 & - \\
& Autonomy & $0.64 *$ & $0.38^{*}$ & 1 \\
\hline
\end{tabular}

*, statistically significant $(p<0.05)$.

To test for metric invariance (factorial invariance), all factor loadings were constrained to be equal across the three generation groups. The chi-square difference test between the configural (M1) versus metric model (M2) was significant $\left(\Delta \chi^{2}[\Delta d f=28]=93.45, p<0.001\right)$. Chi-square is, however, affected by large sample size (Byrne \& Van de Vijver, 2010). Given the fact that the chi-square difference test was based on a large sample size $(N=945)$ and the change in CFI $(\Delta<0.01)$ and RMSEA $(\Delta<0.015)$ was smaller than the suggested cut-off (Cieciuch \& Davidov, 2015; Platania, Morando, \& Santisi, 2020), the assumption could thus be made that there was no appreciable difference between the three generational cohorts regarding the factor loadings of the measured variables. In addition, although the change in SRMR $(\triangle$ SRMR $=0.04)$, was larger than the suggested 0.03 cut-off criteria as were suggested by Cieciuch and Davidov (2015), these authors, however, suggested that CFI should be used as the main criteria because both RMSEA and SRMR are more likely to be affected by sample size and model complexity. This result indicates that the factor loadings of the measured variables were invariant across the three generation groups. 
TABLE 7: Invariance testing between the different generational cohorts.

\begin{tabular}{|c|c|c|c|c|c|c|c|c|c|c|c|}
\hline Model & $\chi^{2}$ & $d f$ & CFI & TLI & RMSEA & SRMR & AIC & BIC & Model comparison & $\Delta \chi^{2}$ & $\Delta \mathrm{CFI}$ \\
\hline M1: Configural invariance & 864.36 & 348 & 0.93 & 0.92 & 0.07 & 0.05 & 38054.75 & 38837.88 & $\mathrm{M} 2$ vs. M1 & $93.45^{*}$ & 0.00 \\
\hline M2: Metric invariance & 957.81 & 376 & 0.93 & 0.92 & 0.07 & 0.09 & 38092.20 & 38739.97 & M3 vs. M1 & $166.73^{*}$ & -0.01 \\
\hline M3: Scalar invariance & 1031.09 & 404 & 0.92 & 0.92 & 0.07 & 0.09 & 38109.49 & 38621.90 & M3 vs. M2 & $73.29 *$ & -0.01 \\
\hline
\end{tabular}

$\chi^{2}$, chi-square statistic; $d f$, degrees of freedom; TLI, Tucker-Lewis index; CFI, comparative fit index; RMSEA, root mean square error of approximation; SRMR, standardised root mean square residual; AIC, Akaike information criterion; BIC, Bayes information criterion.

$*$, statistically significant differences $(p<0.05)$.

To test for scalar (intercept) invariance, all intercepts were constrained to be equal across the three generation groups, in addition to the factor loadings of the latent variables. Although the chi-square difference test between the scalar invariance model (M3) and the metric model (M2) was significant $\left(\Delta \chi^{2}[\Delta d f=28]=73.29, p<0.001\right)$, the large sample size should be taken into consideration. The change in CFI (0.92 vs. 0.93) was equal to the suggested 0.01 criteria $(\Delta \mathrm{CFI}=0.01)$. Also, the change in RMSEA $(\Delta$ RMSEA $=$ 0.00 ) was smaller than the suggested 0.015 cut-off criteria. The change in SRMR $(\triangle$ SRMR $=0.04)$, however, was larger than the suggested 0.03 cut-off criteria (Cieciuch \& Davidov, 2015; Platania et al., 2020) and as indicated previously, could have been affected by sample size and model complexity. These results indicated that both the factor loadings and item intercepts of the measured variables were invariant across the three generation groups. The factor means could thus be compared across the groups.

The factor means across the three generation groups were compared using one-way analysis of variance. There were significant differences across groups: $F=2.84, d f=6$, $p=0.009, \eta_{\mathrm{p}}{ }^{2}=0.009$. Significant differences were found between Gen $X$ and the Boomers. Statistically significant differences were established between levels of psychological ownership and specifically with regard to identity and autonomy. Results indicated that the Boomers (4.96, s.d. $=0.61)$ experienced higher levels of psychological ownership compared with Gen X (4.76, s.d. $=0.69)$. Boomers' levels of identity $(4.77$, s.d. $=0.84)$ and autonomy (4.77, s.d. $=0.82)$ were also significantly higher compared with Gen X's levels of identity $(4.50$, s.d. $=0.96)$ and autonomy $(4.55$, s.d. $=0.99)$.

\section{Discussion}

The purpose of this study was to investigate the measurement equivalence of the SAPOS across three generational cohorts (Boomers, Gen Xers and Millennials) in order to make meaningful inferences and comparisons about psychological ownership across the generational cohorts. The results showed that the original three-dimensional factor structure of the SAPOS proposed by Olckers (2013) and Brits (2016) met all the criteria for an acceptable model fit. In respect of this model, items loaded statistically significantly on all three subscales (identity, responsibility and autonomy) across the generational cohorts. Configural, metric and scalar invariance were established. The three generational cohorts were compared and certain conclusions were made regarding their perceptions of psychological ownership.
Looking at the factor structure of the SAPOS, results indicated that Olckers' (2013) original second-order three-factor model (with psychological ownership as second-order factor and responsibility, autonomy and identity as first-order factors) showed acceptable fit. This factor structure was also confirmed by Brits (2016) in her study. When inspecting the fit indices of the baseline model (overall group) and the three generational cohorts' models, little differentiation was detected (after correlating error terms on items one and six, which were both from the first-order latent variable of identity). In correlating errors between items, we aimed to achieve the optimal fit for the proposed model of Olckers (2013) across the different generations. According to Wang and Wang (2012), correlating errors between items is suitable when items are very similar in wording, which was the case in this study. In respect of the three generational cohorts in the South African organisational context, there is thus a clear distinction between the three different yet complementary components of psychological ownership, namely identity, responsibility and autonomy. No significant cross-loadings were found, meaning that from the view of the different generations, there is a clear distinction between the factors and the items. Across the baseline model and the three generational cohorts' models, the items loaded significantly on the constructs they were developed to measure. This means that the items measured the constructs they were meant to assess. The intercorrelations between the CFA factors across the different groups showed differentiation between the factors.

Measurement invariance was assessed to examine whether the three generational cohorts perceive psychological ownership, as measured by the SAPOS, in the same way. A hierarchical series of models were tested to establish measurement invariance. Firstly, the most basic level of measurement invariance was tested, namely configural invariance. Configural invariance was established between the three generational cohorts. This means that the same item was an indicator of the same latent factor (identity, responsibility and autonomy) in each group (Boomers, Gen X and Millenials), although the factor loadings differed across the groups.

Secondly, metric (factor loading) invariance was assessed. Metric invariance determines the strength of the linear relationship between each factor and its associated item or the observed variable. If metric invariance is achieved, it means that the observed indicator variables (items) measure the same constructs/factors in different groups. In the configural invariance model, no equality constraints were imposed on the values of the hypothesised factor loadings 
across the three generational cohorts, whereas the metric invariance model constrains the factor loadings to be equal in each group (Chen et al., 2005). The chi-square difference test is often used to compare the fit between the two models. The chi-square test should be non-significant. A significant chisquare is an indication of poor fit. A significant chi-square indicates a significant difference between groups suggesting that the metric invariance model is too strict and fails the test of measurement invariance across the groups. However, chi-square statistics are influenced by non-normality and large sample sizes, 'rendering it an impractical and unrealistic criterion on which to base evidence of invariance' (Byrne, \& Stewart, 2006. p. 305). According to Byrne and Stewart (2006) and Cieciuch and Davidov (2015), evidence of invariance should instead be based on the following criteria: (1) acceptable fit of the multigroup model to the data and (2) a CFI difference value of $\leq 0.005$ or 0.01 . In addition, Cieciuch and Davidov (2015) proposed that for larger sample sizes $(N>300)$ a difference value of $<0.015$ for RMSEA and an SRMR difference value $<0.03$ be considered as well. In this study, the chi-square value between the configural and metric model was significant. This significant chi-square value could have been affected by the large sample size of the study $(N=945)$. Following the criteria suggested by Byrne and Stewart (2006) and Cieciuch and Davidov (2015), there is evidence of metric invariance in this study because (1) the multigroup model showed acceptable fit $\chi^{2}=957.81, d f=376$, $\mathrm{CFI}=0.93, \mathrm{TLI}=0.92, \mathrm{RMSEA}=0.07, \mathrm{SRMR}=0.09)$ and $(2)$ the difference in the $C F I(\triangle C F I=0.00)$ value was $\leq 0.01$. Other fit indices as suggested by Chen (2007) were also compared. The change in RMSEA $(\Delta$ RMSEA $=0.00)$ was smaller than the suggested 0.015 cut-off criteria, although the change in SRMR $(\triangle \mathrm{SRMR}=0.04)$ was larger than the suggested 0.03 cut-off criteria. Metric invariance implies that the same factors are measured by the same items for the Boomers, Gen $X$ and the Millennials. It is, however, still uncertain whether the items of the SAPOS have the same origin (intercept) across the three generational cohorts, and therefore scalar invariance should be tested.

The scalar invariance model also shows adequate fit $\left(\chi^{2}=1031.09, d f=404, \mathrm{CFI}=0.92, \mathrm{TLI}=0.92, \mathrm{RMSEA}=0.07\right.$, SRMR $=0.09)$. The change in CFA $(\triangle \mathrm{CFI}=0.01)$ and RMSEA $(\triangle \mathrm{RMSEA}=0.00)$ were equal or smaller than the suggested cut-off. The change in SRMR was greater than the suggested cut-off criteria 0.01 (for metric vs. scalar). Scalar invariance was established meaning that psychological ownership as measured by the SAPOS is measured in the same way across the three generation groups. Respondents from all three generation cohorts thus interpret the items of the SAPOS in the same way.

Although the chi-square difference tests displayed in Table 7 showed that constraining the factor loadings and the intercepts to be equal across the three generational cohorts resulted in significant increases of the $\chi^{2}$ value, model fit remained very similar in terms of the other fit indices. The differences obtained from the various models were, although statistically significant, relatively small. From the results displayed in Table 4, it seems that the differences in the factor loadings across the three generation groups do not present systematic and meaning variation. The change in SRMR in both the metric and scalar invariance models did not meet the suggested cut-off criteria. According to Cieciuch and Davidov (2015), amongst the three indexes, CFI should rather be used as the main criteria because both RMSEA and SRMR are more likely to be affected by sample size and model complexity.

In summary, the second-order model of the psychological ownership as measured by the SAPOS comprising identity, responsibility and autonomy fit the Boomers, Gen $\mathrm{X}$ and the Millennials adequately. The test of measurement invariance indicated that the factor loadings and intercepts were invariant across the generational cohorts and that meaningful comparisons could be made.

Given the adequate level of measurement invariance, the difference between the group means was tested. Results indicated that Boomers displayed significantly higher levels of psychological ownership than Gen X. They specifically also displayed higher levels of identity and autonomy in comparison to Gen X. The possible reasons for Boomer's higher levels of psychological ownership and specifically with regard to identity and autonomy are explained in the discussion to follow.

Boomers have been described as loyal and driven workaholics (Smeak, 2020). They tend to remain at one organisation as they value loyalty towards the organisation (Cogin, 2012; Gursoy et al., 2008). Boomers are more committed to their organisation compared with the other generations (Rani \& Samuel, 2019). It takes time for the development of psychological ownership, especially towards an organisation (Pierce \& Jussila, 2010). A more prolonged association with an object will most probably lead to knowing the target better and developing a sense of ownership towards it. Boomers might experience a higher level of psychological ownership because they tend to remain in an organisation longer compared with the other generations, permitting the development of psychological ownership. Psychological ownership has also been associated with job search behaviour (Pierce \& Jussila, 2010), which implies that people with a sense of possession (i.e. psychological ownership) are likely to maintain their working relationship with their organisation.

Boomers find their identity in their work because they are competitive workaholics who 'live to work' (Smeak, 2020; Van der Walt et al., 2016). Compared with Gen X and Millennials, Boomers need meaningful, purposeful and challenging work and they continuously look for selfimprovement opportunities (Hernaus \& Vokic, 2014; Wong et al., 2008). Moreover, Baby Boomers value job security and a secure working environment and they tend to identify strongly with their organisation (Smola \& Sutton, 2002). Gen $X$ identifies less with their organisation as they place little emphasis on their job and its value. Gen $X$ tends to view their 
organisation as a smaller part of their identity (Wong et al., 2008) compared with the Boomers, as was confirmed by this study. Gen X is not interested in 'investing in targets' because they do not establish a strong linkage with their organisation, resulting in their being unwilling to create, shape or produce within the organisation (Jussila et al., 2015). Their independence and lack of loyalty towards their organisation compared with the Boomers (Lub, Bal, Blomme, \& Schalk, 2016) might reduce the importance they attach to their organisation as part of their identity.

Numerous researchers have reported that Gen $X$ value independence and autonomy (Hernaus \& Vokic, 2014; Lu \& Gursoy, 2016; Lub et al., 2016). The results of this study indicated that Gen X did value autonomy, but their score was significantly lower than that of the Boomers. Gen X, on the one hand, valued informal work environments and flexible working hours, and they are not as intensely involved with their jobs as were Boomers. They prefer to be independent and have complete autonomy whilst enjoying an informal and unstructured work environment (Van der Walt et al., 2016). Boomers, on the other hand, do not want the freedom to schedule their own work; however, they want to determine how they do their work because they view themselves as experienced and want recognition for their experience (Schullery, 2013). Hernaus and Vokic (2014) found that Boomers display higher levels of work autonomy than Gen X and Millennials, as was confirmed by this study.

\section{Limitations and suggestions for future research}

The sample for this study was not evenly distributed in respect of the different generational cohorts (Boomers [ $n=282]$, Gen X [ $n=486]$ and Millennials [ $n=177])$. Moreover, perhaps a more stratified probability sample technique could have been followed where each of the generational cohorts samples were selected in proportion to their size in the population. This would have increased the generalisability of the results.

Similar to other generational studies, a fundamental limitation of this study was the use of cross-sectional data, which does not enable the determination of the causality of effects; although Spector (2019) indicated that there is merit in cross-sectional studies. It is recommended that trends should be explored over time by employing longitudinal research or using time-lag methods. This would allow for comparing participants of the same age at different points in time and for determining if any differences could be ascribed to generational differences rather than to age differences (Twenge et al., 2010). Furthermore, the current research was based on self-evaluations and therefore, might have been biased.

Another limitation of the study was that the age categorisations for generations that are used across the globe (and also in the literature) might be too simplistic. Account should be taken of the statement by Burke et al. (2015) that generational attributes might be affected by socio-political events that create and shape generational cohorts. Therefore, more research is necessary to establish whether there is justification for the broad cut-off points for generations' ages and whether these generational age groups are indeed applicable in the South African context.

Greiff and Sherer (2018), however, warned against the use of 'golden cut-off rules' for the various fit indices and emphasise the fact that these cut-offs should not be generalised to all contexts. They suggest that researchers should statistically identify the items that function differently across groups by employing differential item functioning to supplement the findings obtained from multigroup CFA. The use of differential item functioning was beyond the scope of this study and could perhaps be explored in future research.

\section{Practical implications}

The results of the study indicated that the second-order SAPOS factor structure operates equivalently across the three generational cohorts. Psychological ownership is thus measured similarly across the three generation groups. This has significant practical implications for organisations (Man \& Farquharson, 2015; Olckers \& Du Plessis, 2012). Knowing how generational cohorts differ in their work values and being able to identify how psychological ownership can improve these values might result in better work-related outcomes such as commitment, job satisfaction and the intention to stay with the organisation (Avey et al., 2009; Olckers \& Du Plessis, 2012). Also, knowing how the generational cohorts differ can assist organisations in the development of targeted interventions to develop, nurture and enhance psychological across generations. For example, Gen X should be allowed the freedom to work autonomously (Lu \& Gursoy, 2016; Lub et al., 2016). An informal work environment and freedom to personalise their workspace will most probably enhance GenX's level of psychological ownership towards the organisation. This generation also prefers not to be supervised (Twenge et al., 2010). Millennials will develop a sense of psychological ownership if the organisation can satisfy their technological and lifestyle requirements. Boomers and Millennials value status and extrinsic rewards for their loyalty and attachment towards their organisation (Cogin, 2012); therefore, to enhance their level of psychological ownership, they should be provided with continuous, constructive feedback and be rewarded for their performance. Millennials need to see the meaning and added value of their contributions to the work before they take on full responsibility (Calk \& Patrick, 2017). Therefore, to enhance their psychological ownership, Millenials should be informed in detail of what is expected of them. The provision of clear expectations will assist Millennials in finding meaning in their work. Therefore, their work will most likely become a target of ownership.

\section{Conclusion}

Measurement invariance (on configural, metric and scalar level) was established across three generational cohorts, 
Boomers, Gen X and Millennials indicating that these generations interpret the items of the SAPOS in the same way. Although several studies have made assertions about differences amongst generational cohorts, the issue of using equivalent measures has not been addressed. This study provides empirical evidence to confirm that the three generational cohorts used in this study perceive psychological ownership similarly, and therefore, comparisons can be made between the groups.

\section{Acknowledgements Competing interests}

The authors declare that they have no financial or personal relationships that may have inappropriately influenced them in writing this article.

\section{Authors' contributions}

C.O. and C.B. contributed equally to the design and implementation of the research, to the analysis of the results and to the writing of the manuscript.

\section{Funding information}

This research received no specific grant from any funding agency in the public, commercial or not-for-profit sectors.

\section{Data availability}

The authors confirm that the data supporting the findings of this study are available within the article.

\section{Disclaimer}

The views and opinions expressed in this article are those of the authors and do not necessarily reflect the official policy or position of any affiliated agency of the authors.

\section{References}

Aggenbag, A. (2015). Job embeddedness and psychological ownership: Are they related? Unpublished master's dissertation. Pretoria: University of Pretoria.

Avey, J., Avolio, B., Crossley, C., \& Luthans, F. (2009). Psychological ownership Theoretical extensions, measurement and relation to work outcomes. Journal of Organisational Behaviour, 30(2), 173-191. https://doi.org/10.1002/job.583

Becton, J.B., Walker, H.J., \& Jones-Farmer, A. (2014). Generational differences in workplace behavior. Journal of Applied Psychology, 44(3), 175-189. https://doi. org/10.1111/jasp.12208

Bencsik, A., Horváth-Csikós, G., \& Juhász, T. (2016). Y and Z generations at workplaces. Journal of Competitiveness, 8(3), 90-106. https://doi.org/10.7441/ joc.2016.03.06

Bosco, S., \& Harvey, D. (2013). Generational effects on recruitment and workplace productivity. Northeast Business \& Economics Association Proceedings, pp. 17-20, Bristol, IN: Northeast Business \& Economics Association.

Brits, N. (2016). Assessing a short version of the South African Psychological Ownership Questionnaire (SAPOS). Unpublished master's dissertation. Pretoria: University of Pretoria.

Brown, G., Crossley, C., \& Robinson, S.L. (2014). Psychological ownership, territoria behavior, and being perceived as a team contributor: The critical role of trust in the work environment. Personnel Psychology, 67(2), 463-485. https://doi. org/10.1111/peps.12048

Brown, G., Lawrence, T.B., \& Robinson, S.L. (2005). Territoriality in organizations. Academy of Management Review, 30(3), 577-594. https://doi.org/10.5465/ amr.2005.17293710

Browne, M. (2001). An overview of analytic rotation in exploratory factor analysis. Multivariate Behavioral Research, 36(1), 111-150. https://doi.org/10.1207/ S15327906MBR3601_05
Budruk, M. (2010). Cross-language measurement equivalence of the place attachment scale: A multigroup confirmatory factor analysis approach. Journal of Leisure Research, 42(1), 25-42. https://doi.org/10.1080/00222216.2010.11950193

Burke, R.J., Cooper, C.L., \& Antoniou, A.G. (2015). The multi-generational and aging workforce: Challenges and opportunities. Cheltenham: Edward Elgar Publishing Ltd.

Byrne, B.M., \& Stewart, S.M. (2006). Teacher's corner: The MACS approach to testing for multigroup invariance of a second-order structure: A walk through the process. Structural Equation Modeling, 13(2), 287-321. https://doi.org/10.1207/ s15328007sem 13027

Byrne, B.M., \& Van de Vijver, F.J.R. (2010). Testing for measurement and structural equivalence in large-scale cross-cultural studies: Addressing the issue of nonequivalence. International Journal of Testing, 10(2), 107-132. https://doi. org/10.1080/15305051003637306

Calk, R., \& Patrick, A. (2017). Millennials through the looking glass: Workplace motivating factors. The Journal of Business Inquiry, 16(2), 131-139. Retrieved from http:www.uvu.edu/woodbury/jbi/volume16

Chai, D.S., Song, J.H., \& You, Y.M. (2020). Psychological ownership and openness to change: The mediating effects of work engagement, and knowledge creation. Performance Improvement Quarterly, 33(3), 305-326. https://doi.org/10.1002/ piq.21326

Chen, F., Sousa, K., \& West, S. (2005). Testing measurement invariance of secondorder factor models. Structural Equation Modeling, 12(3), 471-492. https://doi. org/10.1207/s15328007sem1203_7

Chen, T., Dodds, S., Finsterwalder, J., Witell, L., Cheung, L., Falter, M., ... McColl-Kennedy, J.R. (2020). Dynamics of well-being co-creation: A psychological ownership perspective. Journal of Service Management, July, 1-24. https://doi.org/10.1108/ JOSM-09-2019-0297

Chen, F.F. (2007). Sensitivity of goodness of fit indexes to lack of measurement invariance. Structural Equation Modeling: A Multidisciplinary Journal, 14(3), 464-504. https://doi.org/10.1080/10705510701301834

Cieciuch, J., \& Davidov, E. (2015). Establishing measurement invariance across online and offline samples. A tutorial with the software packages Amos and Mplus. Studia Psychologica, 15(2) 83-99. https://doi.org/10.5167/uzh-170024

Cogin, J. (2012). Are generational differences in work values fact or fiction? Multicountry evidence and implications. The International Journal of Human Resource Management, 23(11), 2268-2294. https://doi.org/10.1080/09585192.2011.610967

Durocher, S., Bujaki, M., \& Brouard, F. (2016). Attracting millennials: Legitimacy management and bottom-up socialization processes within accounting firms. Critical Perspectives on Accounting, 39, 1-24. https://doi.org/10.1016/j.cpa.2016.02.002

Fornell, C., \& Larcker, D. (1981). Evaluating structural equation models with unobservable variables and measurement error. Journal of Marketing Research 18(1), 39-50. https://doi.org/10.2307/3151312

Greiff, S., \& Scherer, R. (2018). Still comparing apples with oranges? Some thoughts on the principles and practices of measurement invariance testing. European Journa of Psychological Assessment, 34(3), 141-144. https://doi.org/10.1027/1015$5759 / \mathrm{a} 000487$

Gursoy, D., Chi, C., \& Karadag, E. (2013). Generational difference in work values and attitudes among frontline and service contact employees. International Journal of Hospitality Management, 32, 40-48. https://doi.org/10.1016/j.ijhm.2012.04.002

Gursoy, D., Maier, T., \& Chi, C. (2008). Generational differences: An examination of work values and generational gaps in the hospitality workforce. Internationa Journal of Hospitality Management, 27(3), 448-458. https://doi.org/10.1016/j. ijhm.2007.11.002

Hair, J.F., Black, W.C., Babin, B.J., \& Andersen, R.E. (2014). Multivariate data analysis. Essex: Pearson.

Henseler, J., Ringle, C.M., \& Sarstedt, M., (2015). A new criterion for assessing discriminant validity in variance-based structural equation modeling. Journal of the Academy of Marketing Science, 43, 115-135. https://doi.org/10.1007/ s11747-014-0403-8

Hernaus, T., \& Vokic, N. (2014). Work design for different generational cohorts: Determining common and idiosyncratic job characteristics. Journal of Organisational Change Management, 27(4), 615-641. https://doi.org/10.1108/ JOCM-05-2014-1004

Heyns, M.M., \& Kerr, M.D. (2018). Generational differences in workplace motivation. SA Journal of Human Resource Management/SA Tydskrif vir Menslikehulpbronbestuur, 16(0), a967. https://doi.org/10.4102/sajhrm.v16i0.967

Jafri, H. (2015). Increasing employee performance through improved sense of ownership. An International Journal of Management Studies, 5(2), 84-90. https:// doi.org/10.11127/gmt.2015.06.06

Jussila, I., Tarkiainen, A., Saestedt, M., \& Hair, J. (2015). Individual psychological ownership: Concepts, evidence and implications for research in marketing. Journal of Marketing Theory and Practice, 23(2), 121-139. https://doi.org/10.108 $0 / 10696679.2015 .1002330$

Kline, R.B. (2016). Principles and practice of structural equation modeling. New York, NY: The Guilford Press.

Lu, A., \& Gursoy, D. (2016). Impact of job burnout on satisfaction and turnover intention: Do generational differences matter? Journal of Hospitality and Tourism Research, 4O(2), 210-235. https://doi.org/10.1177/1096348013495696

Lub, X., Bal, P., Blomme, R., \& Schalk, R. (2016). One job, one deal...or not: Do generations respond differently to psychological contract fulfillment? The International Journal of Human Resource Management, 27(6), 653-680. https:// doi.org/10.1080/09585192.2015.1035304 
Lyons, S.T., Schweitzer, L. \& Ng, E.S. (2015). How have careers changed? An investigation of changing career patterns across four generations. Journal of Managerial Psychology, 30(1), 8-21. https://doi.org/10.1108/JMP-07of Manageric

Man, T., \& Farquharson, M. (2015). Psychological ownership in team-based entrepreneurship education activities. International Journal of Entrepreneurial Behaviour and Research, 21(4),600-621. https://doi.org/10.1108/JJEBR-11Behaviour

Massingham, P., \& Chandrakumara, A. (2019). Generational differences in work values and attitudes: Reintroducing retirees to the workforce. Journal of Population Ageing, 12, 491-513. https://doi.org/10.1007/s12062-019-09250-w

Muthén, L.K., \& Muthén, B.O. (2019). Mplus (Version 8.2) [Statistical software]. Los Angeles, CA: Muthén \& Muthén.

Olckers, C. (2013). Psychological ownership: Development of an instrument. SA Journal of Industrial Psychology/SA Tydskrif vir Bedryfsielkunde, 39(2), Art. \#1105, 13 pages. https://doi.org/10.4102/sajip.v39i2.1105

Olckers, C., \& Du Plessis, Y. (2012). The role of psychological ownership in retaining talent: A systematic literature review. SA Journal of Human Resource Management/ SA Tydskrif vir Menslikehulpbronbestuur, 10(2), Art. \#415, 18 pages. https://doi. org/10.4102/sajhrm.v10i2.415

Olckers, C., Du Plessis, M., \& Casaleggio, R. (2019). Authentic leadership, organisational citizenship behaviours, and intention to quit: The indirect effect of psychological ownership. South African Journal of Psychology, 50(3), 1-14. https://doi. org/10.1177/0081246319891658

Olckers, C., \& Van Zyl, L.E. (2017). Measuring psychological ownership: A critica review. In C. Olckers, L.E. Van Zyl, \& L. Van der Vaart (Eds.), Theoretical orientations and practical applications of psychological ownership (pp. 61-78) Cham: Springer.

Pallant, J. (2007). SPSS survival manual: A step by step guide to data analysis using SPSS for Windows (7th edn.). New York, NY: McGraw-Hill.

Pierce, J., \& Jussila, I. (2010). Collective psychological ownership within the work and organisational context: Construct introduction and elaboration. Journal of Organizational Behavior, 31(6), 810-834. https://doi.org/10.1002/job.628

Pierce, J., Kostova, T., \& Dirks, K. (2001). Towards a theory of psychological ownership in organisations. The Academy of Management Review, 26(2), 298-310. https:// doi.org/10.5465/amr.2001.4378028

Pierce, J.L., Kostova, T., \& Dirks, K.T. (2003). The state of psychological ownership Integrating and extending a century of research. Review of General Psychology, 7(1), 84-107. https://doi.org/10.1037/1089-2680.7.1.84

Platania, S., Morando, M., \& Santisi, G. (2020). Psychometric properties, measurement invariance, and construct validity of the Italian version of the Brand Hate Short Scale (BHS). Sustainability, 12(5), 2103. https://doi.org/10.3390/su12052103

Rani, N., \& Samuel, A.A. (2019). Generational differences in relationship between prosocial identity fit and affective commitment. International Journal of Organization Theory \& Behavior, 22(3), 259-277. https://doi.org/10.1108/ IJOTB-07-2018-0075

Raykov, T. (2009). Evaluation of scale reliability for unidimensional measures using latent variable modeling. Measurement and Evaluation in Counseling and Development, 42(3), 223-232. https://doi.org/10.1177/0748175609344096
Ryu, E. (2011). Effects of skewness and kurtosis on normal-theory based maximum likelihood test statistic in multilevel structural equation modeling. Behavioral Research, 43, 1066-1074. https://doi.org/10.3758/s13428-011-0115-7

Sarraf, A.R.A., Abzari, M., Isfahani, A.N., \& Fathi, S. (2017). Generational differences in job engagement: A case study of an industrial organization in Iran. Industria and Commercial Training Journal, 49(3), 06-115. https://doi.org/10.1108/ICT10-2016-0068

Schullery, N. (2013). Workplace engagement and generational differences in values. Business Communication Quarterly, 76(2), 252-265. https://doi.org/10.1177/ 1080568813476543

Smeak, R. (2020). Safety in the multigeneration workplace. Professional Safety Journal, May, 22-27. Retrieved from https://www.assp.org/docs/default-source/ psj-articles/f1smeak_0520.pdf?sfvrsn=2

Smola, K., \& Sutton, C. (2002). Generational differences: Revisiting work values for the new millennium. Journal of Organizational Behaviour, 23(4), 363-382. https:// doi.org/10.1002/job.147

Spector, P.E. (2019). Do not cross me: Optimizing the use of cross-sectional designs Journal of Business and Psychology, 34(2), 125-137. https://doi.org/10.1007/ s10869-018-09613-8

Srinivasan, V. (2012). Multi generations in the workforce: Building collaboration Management Review, 24(1), 48-66. https://doi.org/10.1016/j.iimb.2012.01.004

Suomäki, A., Kianto, A., \& Vanhala, M. (2019). Work engagement across different generations in Finland: A qualitative study of Boomers, Yers and Xers. Knowledge Process Management, 26(2), 140-151. https://doi.org/10.1002/kpm.1604

Twenge, J., Campbell, S., Hoffman, B., \& Lance, C. (2010). Generation differences in work values: Leisure and extrinsic values increasing social and intrinsic values decreasing. Journal of Management, 36(5), 1117-1142. https://doi.org/10.1177/ 0149206352246

Van der Walt, F., Jonck, P., \& Sobayeni, N.C. (2016). Work ethics of different generational cohorts in South Africa. African Journal of Business Ethics, 10(1) 52-66. https://doi.org/10.15249/10-1-101

Van Dyne, L., \& Pierce, J. (2004). Psychological ownership and feelings of possession: Three field studies predicting employee attitudes and organizational citizenship behavior. Journal of Organizational Behavior, 25(4), 439-459. https://doi. org/10.1002/job.249

Wang, J., \& Wang, X. (2012). Structural equation modeling: Applications using Mplus Chichester: Wiley \& Sons.

Weeks, K.P., Weeks, M., \& Lomg, N. (2017). Generational perceptions at work in-group favoritism and out-group stereotypes. Equality, Diversity and Inclusion: An International Journal, 36(1), 33-53. https://doi.org/10.1108/EDI-07-2016-0062

Wong, E., Gardiner, E., Lang, W., \& Coulon, L. (2008). Generational differences in personality and motivation: Do they exist and what are the implications for the workplace? Journal of Managerial Psychology, 23(8), 878-890. https://doi. org/10.1108/02683940810904376

Wood, J.C. (2019). Millennials in the workplace: Mystery or magic? Dispute Resolution Journal, 74(1), 111-120.

Yuan, K., \& Chan, W. (2016). Measurement invariance via multi-group SEM: Issues and solutions with chi-square-difference tests. Psychological Methods, 21(3) 405-426. https://doi.org/10.1037/met0000080 